\title{
The Morphology of Phylloglossum Drummondii, Kunze.
}

BY

\author{
K. SAMPSON, B.Sc., \\ Post-gradisate Student, Royal IJolloway College, University of London.
}

With five Figures in the Text.

Contents.

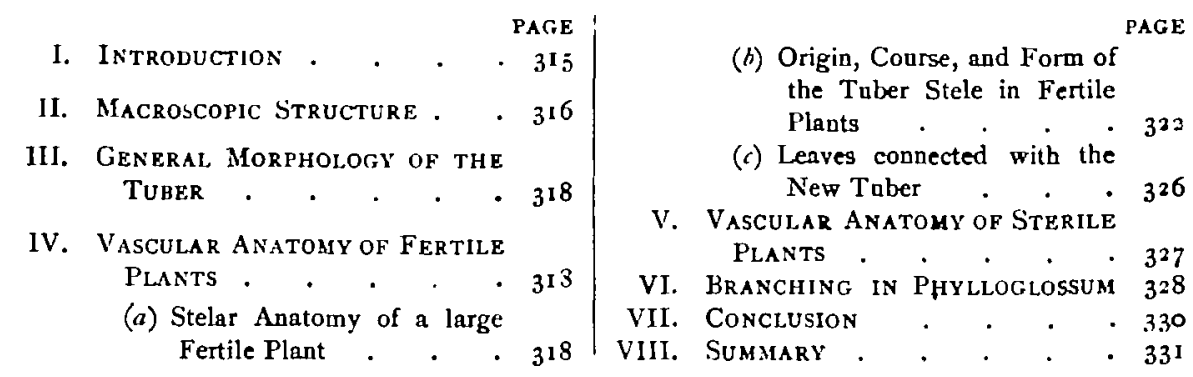

\section{INTRODUCTION.}

PHYLLOGLOSSUM Drummondii was described for the first time in 1843 by Kunze, who regarded the genus as occupying a position intermediate between the Lycopodiaceae and the Ophioglossaceae, its supposed affinity with the latter family being founded on a superficial resemblance in habit to Ophioglossum Bergianium. ${ }^{1}$ The following year Roeper associated Phylloglossim with the Lycopodiaceae, and in that family it has been placed by all later writers. ${ }^{8}$

While the anatomy and general structure have been dealt with by Mettenius, ${ }^{3}$ Bertrand, ${ }^{4}$ and Bower, ${ }^{5}$ no satisfactory conclusion has been reached in regard to the morphology of its annual tuber. Mettenius compared the yearly tuber with that of Orchis and the dropper of Tulipa, but, on the ground that these organs are structurally different, he maintained that the comparison was of little use. Bertrand described the anatomy of Phylloglossim in great detail, but he left the problem of the morphology of its tuber unsolved. Bower followed Treub in comparing the yearly

1 Kanze : Bot. Zeit., 1843.

Roeper : Zur Flora Necklenburgy, ii, 1844.

1 Mettenius: Bot. Zeit., 1867.

- Hertrand : Arch. bot. du Nord de la France, No5. 30-34, 1884.

- Bower : Phil. Trans., 1886.

[Annale of Botany, Vol. XXX. No. CXVIII. April, 1916.] 
growth of Phylloglossum with the embryonic form of Lycopodium cermumm, noting a resemblance between the tuber of the former, and the 'protocorm ' of the latter.' His conception of Phylloglossum as 'a permanently embryonic form of Lycopod' received wide acceptance. ${ }^{2}$

Wernham, drawing an analogy between the tuber of Phylloglossum and the droppers of certain Monocotyledonous plants, suggested that like these it is partly foliar and partly axial. His investigation, however, was limited to two specimens. ${ }^{3}$

The morphology of the annual tuber of Phylloglossum is, then, an open question. Moreover, such solutions of the problem as have been put forward are hypothetical, and based on analogy rather than on a strict examination of anatomical structure. Since 'the question of the position of Phylloglossum chiefly turns upon the view we take of its annual tuber and its protophylls,' it is of exceptional importance that its morphology be understood. When, therefore, by the kindness of Professor Benson a quantity of material was placed at my disposal, I decided to discover if a re-investigation of its anatomy might not throw light on the problem of its morphology. The result of this work is set forth in the present paper.

\section{Macroscotic Structure.}

The general features of a fertile plant of Phylloglossum, at a stage previous to spore-dispersal, may be seen from Fig. I. This figure was drawn from a specimen about $1 \frac{1}{2}$ " high, bearing above the level of the ground five long tapering leaves, and a smooth cylindrical axis (P) terminating in a compact strobilus (S); while unbranched, horizontally running roots ( $R$ ) and two tuberous bodies are buried in the substratum. The shorter and more slender tuber, $t$, belongs to the growth of the present year, the other; $T$, dates from the previous season. The former, at the age figured, appears as a smooth exogenous outgrowth about $\frac{1}{4}$ "long, and slightly swollen at the free end, in which may be seen the outline of an enclosed bud, $b$. The tuber is an organ of perennation; it is set free at the end of the season by the decay of other parts of the plant, and after a period of rest germinates, the activities of the enclosed bud producing roots, leaves, frequently a cone, and always another tuber. These organs constitute the yearly growth of the plant. All that remains of the growth of the previous season is the torn sheath, $s h$, of the old tuber.

The general structure of Phylloglossum will be clearer, if reference be made here to the research of Professor Bower on the germination of

$\perp$ Treub: Ann. Jard. Buit., vol. 8, $188 y-90$.

- For Bower's more recent views, se Presidential Address to Section K (Botany), British Associa. tion, Australia, 1914.

Wernham : Ann. of Bot., vol. xxiv, 1912, p. 335.

1 Hower : loc. cit., 1914 , p. 6. 
perennating tubers, by means of which he was able to trace the development of a new tuber, and the origin of the bud enclosed in its free end. ${ }^{1}$ A new tuber appears first as a projecting mass of tissue with the growing point situated in a depression in the centre. The growing point, however, does not long maintain its central position, becoming first sunk, and then inverted owing to the rapid and unequal growth of surrounding tissue. Finally, it takes the form of a conical mass of meristematic tissue at the base of a narrow channel. This channel, although less distinct in older specimens, never becomes completely obliterated. Its position can generally be recognized, at least in transverse sections of a tuber, by the smaller cells which surround it. It had earlier been observed by Bertrand, and called the 'canal de Braun'.?

This protected position of the bud, and the fact that by intercalary growth it is carried some distance into the substratum, are features showing a marked specialization for a geophytic habit. The tuber can, however, be regarded also as a means of vegetative propagation, since more than one may be formed during the season. ${ }^{3}$

In the course of this investigation two different collections of material were examined-the one which I owe to the kindness of Professor F. E. Weiss was obtained from New Zealand, the other was made in SouthWest Australia by Professor Benson in midwinter, August 3, 19I4. This collection consisted of over one hundred plants, about one-third of which were fertile, showing features similar to those of the specimen

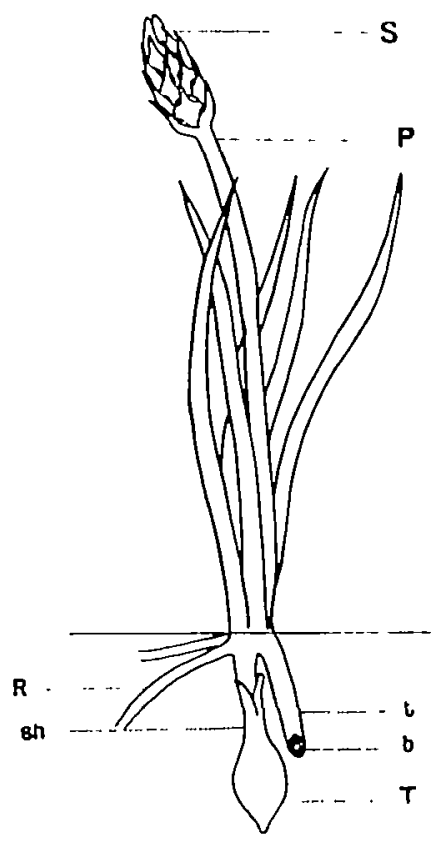

FiG. I. figured. Many of the sterile plants were very young, bearing only one or two leaves, but, like the fertile plants, each possessed one new tuber. The New Zealand specimens had cvidently been collected later in the season, and, moreover, they were on the whole better developed plants. Five were exceptionally interesting in that each possessed two new tubers. These plants had been set aside by Professor Weiss for further investigation, and were with great generosity handed over to me.

1 Bower : loc. cit, 1886.

Bertrand : loc. cit, 1884 .

Thomas: Proc. Roy. Soc., igol-2, p. zgo. 


\section{iII. Glinekal Mokpiology of the Tuber.}

The tuber of Playlloglossum has in turn been compared with the adventitious buds borne on the roots of Ophioglossum, ${ }^{1}$ the tuber of Orchis, ${ }^{2}$ the droppers of certain Monocotyledons, ${ }^{3}$ and the 'protocorm' of $L$. ceriutum. ${ }^{4}$

The present paper seeks to bring forward anatomical data which throw new light upon the morphology of this plant. It is suggested that Phyllo. glossum is derived from some Lycopod possessing a branched vegetative system, which has become reduced and specialized in the adoption of a geophytic habit. The sharply defined pedicillate cone and the specialized storage tuber are advanced characters, and the juxtaposition of these with the frequent occurrence of feebly developed leaves and the absence of phloem from the stem is evidence that Phylloglossum is a reduced form. Examples of branching in Phylloglossum have hitherto been limited to a few isolated cases of dichotomy of the strobilus, but, as a result of an anatomical study, it is believed that branching occurs at least once in the yearly growth of every fertile plant, namely, on the formation of its annual tuber.

The details in vascular anatomy, upon which this view is based, will be dealt with under the following heads:

(a) Stelar a natomy of a large fertile plant.

(b) Origin, form, and course of the tuber stele in fertile plants.

(c) Leaves connected with the tuber stele.

\section{Vascular Anatomy of liertile Plants.}

\section{(a) The Stelar Anatomy of a large Fertile Plant.}

Considered generally, the most striking features in the internal anatomy of Phylloglossum are the frequently medullated protostele, the mesarch position of the protoxylem, and the marked degradation of vascular tissue. The last point is illustrated by the almost complete absence of phloem, the breakdown of the protoxylem in the leaf-traces and in the stem, and the frequent occurrence of weakly formed tracheides.

In Phylloglossum the plan of the stele depends largely on the sizc of the plant and the number and position of tubers, leaves, and roots, and it is therefore not easy to give a general description. If Phylloglosstun be a form which has suffered reduction relatively recent in descent, the largest and best developed specimens would be those in which the more primitive features might be expected to occur. It is

1 van Tieghem : Recherches sur la symétrie de structure des plantes vasculaires. 1871 .

Mettenius: loc. cit., I867.

Wernham : loc. cit., 1912.

+ Treub : loc. cit., 185y-9o. 
for this reason that a description of the best differentiated plant available is given first.

The plant in question is shown in Fig. 2, A. It bears on one side a large new tuber above which is situated a leaf, $s l$, somewhat shorter than the normal leaves of the plant (see p. 326). On the opposite side, two small protuberances may be distinguished, one of which represents an abortive tuber, $t^{\prime}$, the other, $r l$, a much reduced leaf. The fact that there is in this plant an attempt to form a second new tuber will be dealt with later (p. 328 ); the importance of the plant in the present connexion lies in the anatomy of the well-developed tuber and its relation to the stele of the main axis. Before dealing with this, the general plan of the stele must be mentioned.

At the base of a fertile plant the entering root-strands unite to form a medullated protostele, which, interrupted by frequent small gaps,

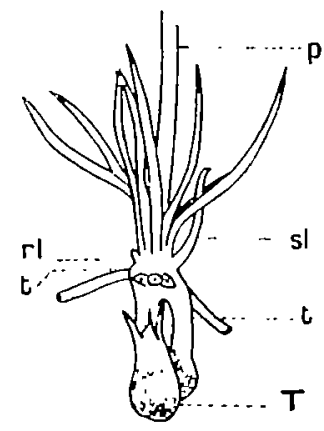

A

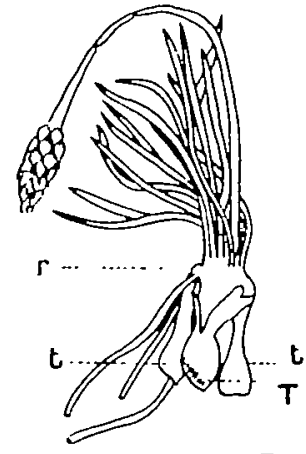

B

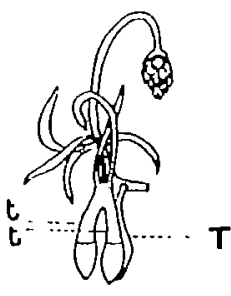

C

FIG. 2.

passes into the peduncle of the cone, and by repeated division supplies the sporophylls. The vascular supply of the new tuber is given off but a short distance above the level of the roots. The leaf-traces, which consist of a single mesarch strand of xylem, are often given off so near the base of the plant that they are in direct connexion with the rootstrands.

The structure of the present specimen will be clearer if sections are described, proceeding upwards from the base of the plant. In Fig. 3, sects. 9, 8, and 7 (drawn with the Abbé camera), the entering rootstrands are seen to unite to form the main stele, which consists, at this level, of anastomosing meristeles arranged round a central mass of parenchyma. In sect. 6 , in position corresponding to the large central stele of previous sections, two steles are cut across, one consisting of a number of meristeles arranged roughly along two sides of a square, the other, a compact, medullated mass of xylem, with a well-marked gap, $g$, on the inner side. Both steles are associated with the exit of leaf-traces; in 
the smaller stele one passes off from each edge of the gap. This stele is also connected with the vascular supply of a root. In the same section (sect. 6) the strand of the tuber, $t$, is seen, closely associated with
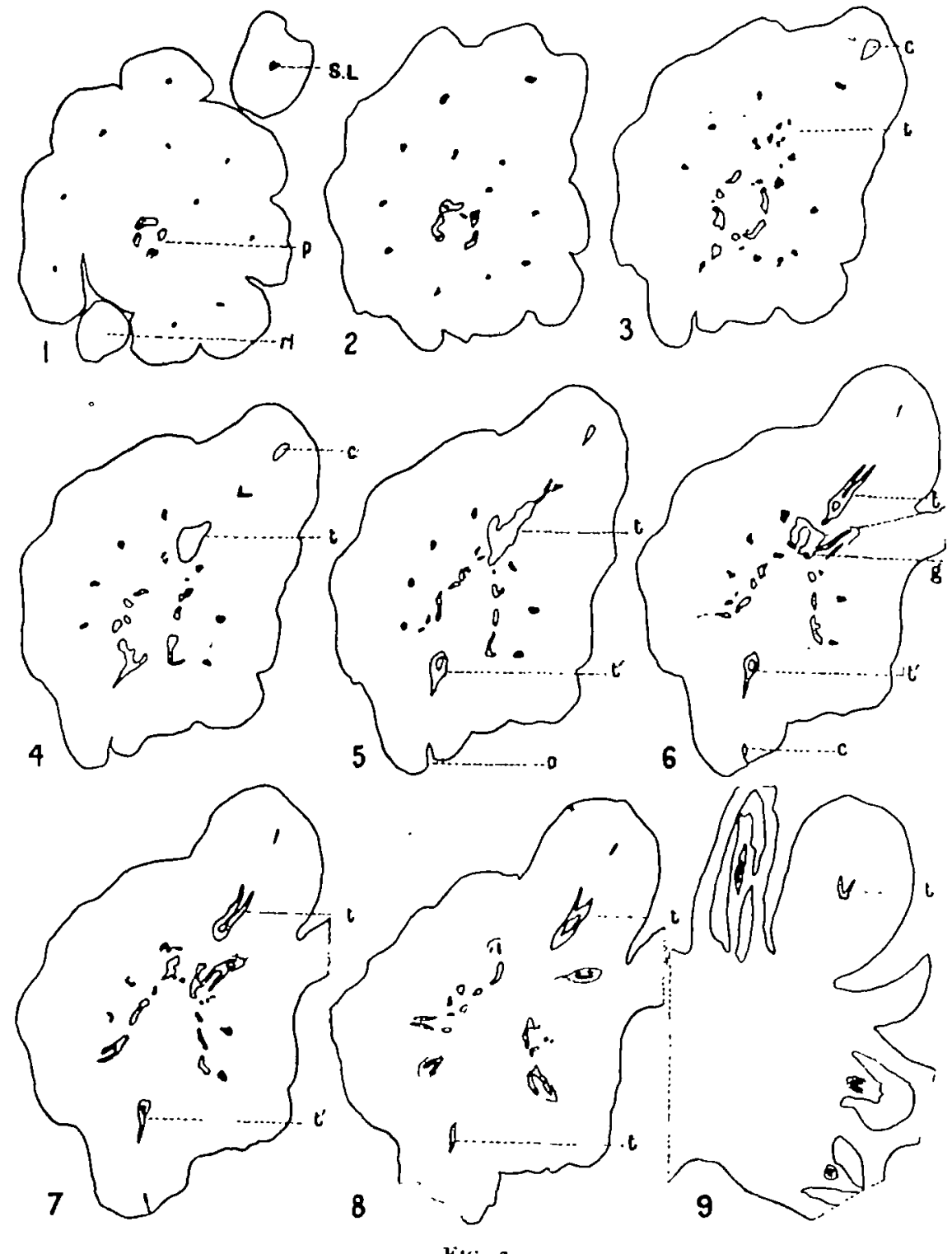

Fic. 3 .

the compact central stele. Higher up the two are united, forming a solid mass of xylem, which is surrounded by the three leaf-traces, which emerged lower down, and a fourth, which is just being given off (sect. 5). 
In higher sections this solid mass of xylem decreases rapidly in size (sect. 4), and finally dies out (sects. 3 and 2).

The bearing of these facts on the relation of the tuber to the main axis is clear from the vertical plan of the stele given in Fig. 4, A, which shows the relative position of the sections just described. On the righthand side of the diagram is a large tuber, the stele of which makes a
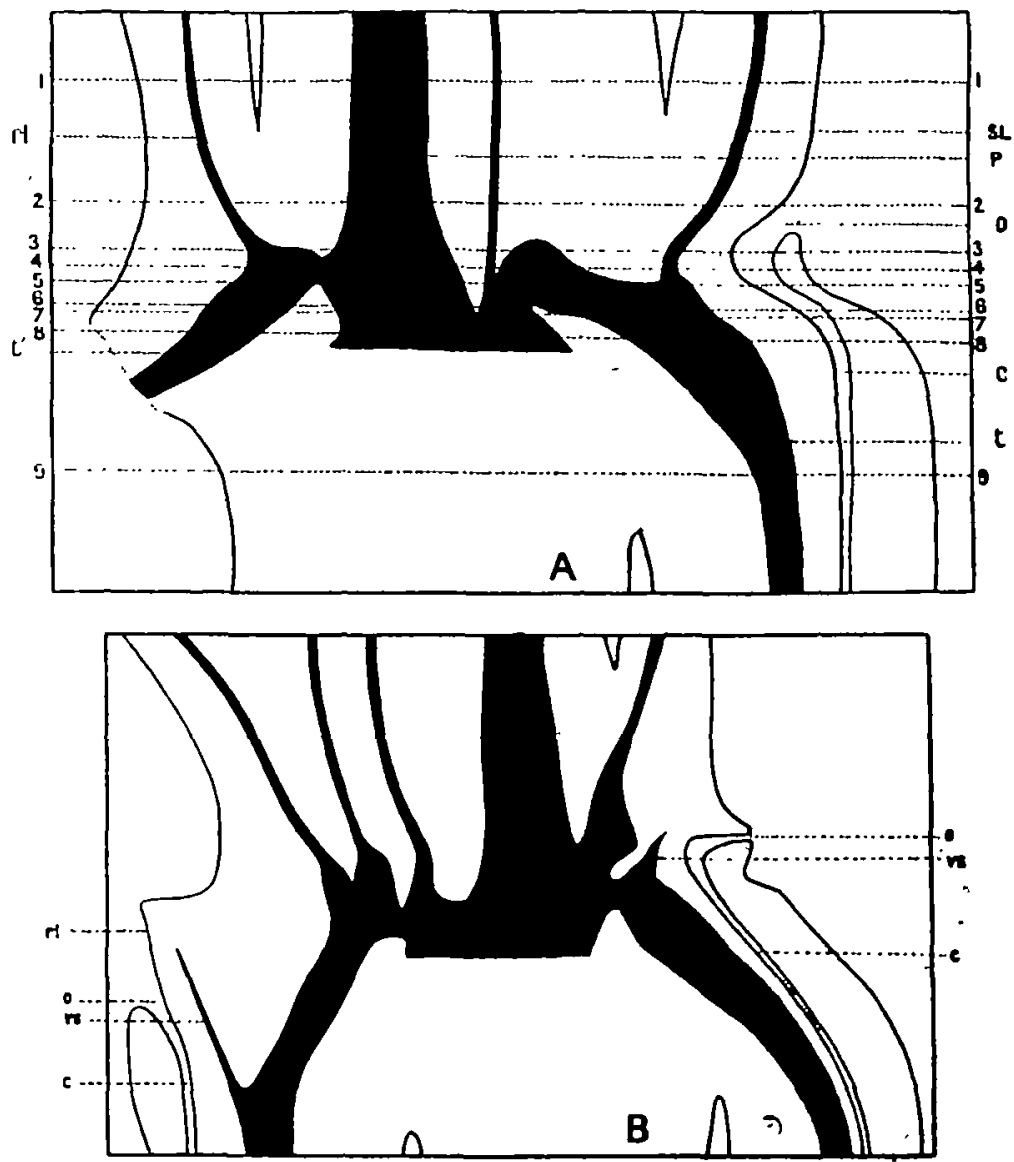

FIG. 4 .

sharp upward bend before passing out and down the shaft of the tuber. The result is that sections below the bend cut the tuber stelc in two places (sect. 6), while sections at a higher level cut the bend itself, and, therefore, show but a single mass of xylem (sects. 5 and 4). The collection of isolated tracheides in sect. 3 represents the highest part of the bend.

The most important features in the stelar anatomy of the plant considered may be summed up as follows: At the base of the plant 
a medullated stele divides, each daughter stele showing a gap on the inner surface. ${ }^{1} \quad$ The smaller daughter stele, making a sharp bend, supplies the new tuber. The original gap is not continued over the bend, but it appears as the stele of the tuber passes out, giving it a characteristic U-form. From the tuber stele several leaf-traces pass out, constructed as those which arise from the main axis, and supplying leaves which number among those of the yearly growth.

The origin of the tuber stele from the stem, its structure, and its connexion with leaf-traces, point to one conclusion, namely, that it is morphologically a branch. In the following pages it will be secn if these features are sufficiently constant in fertile plants to justify this view.

(b) The Origin, Conss, and Form of the Tuber Stele in Fertilc Plants.

In the preceding section of this paper a plant was described, which is to a certain extent unique, at least in the material upon which this investigation was made. Its singularity consists, not so much in any particular feature, as in the fact that it combines several features of supreme importance in a morphological study. The aim of the present section is an examination of these features as they occur in other fertile plants.

Owing to the diversity in stelar anatomy which fertile plants show, it seems best to begin with a brief description of the tuber stele and its relation to the main axis in three distinct cases.

Fig. 5 gives a series of transverse sections of a large fertile plant with a single new tuber. Sect. $I$, through the base of the peduncle, shows the stele as an almost continuous ring of xylem surrounding a relatively large pith. In sect. 2 this ring possesses a very distinct break at one side, the xylem being somewhat horseshoe-shaped, with cortex and medulla continuous through the gap. In the cortex facing this gap are three leaftraces, which later become connected by tracheides with one another and with the edges of the gap (sect. 3), with the result that a tube of xylem is again formed of diameter nearly twice that of the ring seen in a higher section. This tubular condition lasts for one or two sections only, as the stele divides to form two arcs of xylem, one of which supplies the tuber, while the other breaks up to form the root-strands (sects. 4, 5, and 6). It is important to note that the arc which passes out into the tuber is that connected above with the three leaf-traces already mentioned.

The origin of the vascular supply to the tuber in this plant resembles, in several respects, that of the stunted tuber now to be described. We find, as before, at the base of the peduncle a ring of xylem, in which only small gaps occur (Fig. 3, sect. I). Lower down a break appears on one side of the stele, giving it a horseshoe form in cross-section (sect. 2). Later

1 Cf. the gaps occurring at each dichotomy of the axis in members of the Lepidodendreae, which possess medullated steles. 
Phylloglossum Drummondii, Kunze.
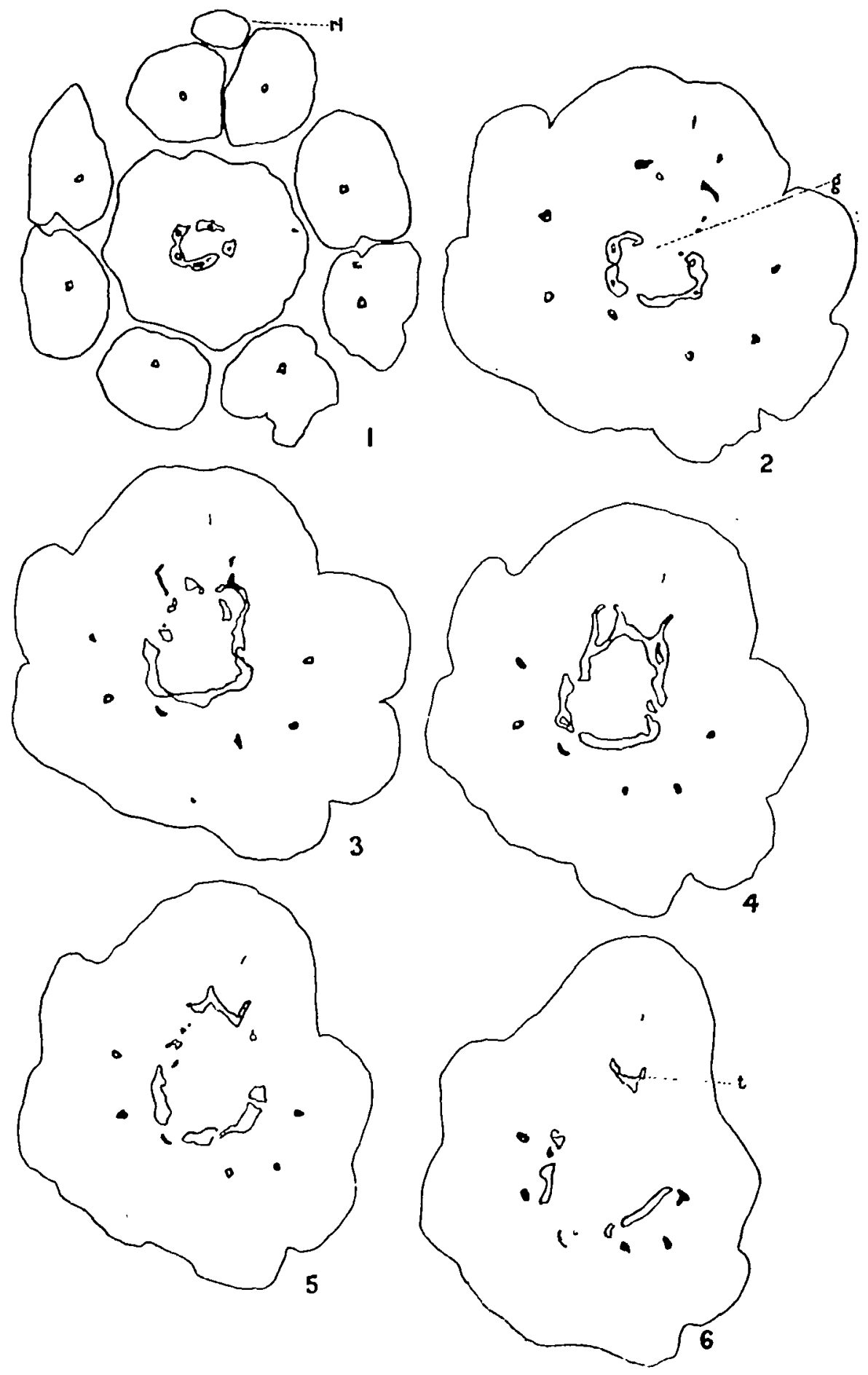

FIG. 5 . 
this gap is closed, in this case by xylem, which appears between the edges of the gap and connects the stele with a single leaf-trace (sects. 3 and 4 ). It is this part of the stele which supplies the strand for the new tuber. The difference between the tuber strands, as they leave the stele in the two plants, depends partly on the fact that the tuber is far better developed in the one case than in the other. Whereas, in the plant with a single tuber, the stele divides almost equally, in the plant now under consideration only a relatively small mass of xylem passes out to the stunted tuber. A difference in form may also be noted, the stele of the stunted tuber being from the first a compact strand of xylem with a small core of enclosed parenchyma.

The stcle of one more fertile plant has yet to be described, since it is, perhaps, more typical of the smaller fertile plants in which the vascular tissue is less well developed. The plant in question possessed a cone, six leaves, and a somewhat slender new tuber. At the base of the peduncle two separate strands of xylem are found instead of a hollow cylinder as in larger plants. Lower down these increase in size, and a third strand appears, connected with a leaf-trace which joins the stele relatively early. The stele now shows a form roughly comparable with the horseshoeshaped stele found at a corresponding level in larger plants, but it is less striking since the stele in the peduncle is already interrupted by large gaps. $^{1}$ In this plant no leaf-traces are connected with the vascular supply of the tuber. It arises from the medullated stele as a small arc of xylem, and, as it passes down the shaft of the tuber, it early becomes a slender cylindrical strand.

In two of the three plants just described, a distinct break in the stele of the main axis was observed immediately above the point at which the strand of the new tuber is given off. Though less conspicuous in the smaller fertile plants, owing to the weaker development of the stele, this break was found in eleven of the twelve cases examined, while the one specimen in which a gap was not found showed a thinning of the xylem in a corresponding position. Although this gap generally extends for a very short distance, the sections in which it does occur present a most charactcristic appearance, and one which has been noted by previous workers. Thus Wernham concludes that the 'noticeable $U$-form of the upper part of the stem is, perhaps, the most striking feature', ${ }^{2}$ while Jeffrey describes Phylloglossum as having 'a tubular stele, which, in the lower tuberous portion of the stem, constitutes in cross-section an almost continuous horseshoc of xylem'. He states also that 'the opening in the horseshoe corresponds to the outgoing strand, which passes into the resting tuber'?

1 The stelar gaps of Phylloglossum are not regarded as foliar gaps, though sometimes found in apparent connexion with leaf-traces (Jeffrey: Bot. Gaz., vol. xlvi, 1908, p. 245).

2 Wernham : loc. cit., p. 33 S. J Jeffiey : loc. cit, p. 244. 
The fact that a gap is caused in the main stele by the exit of the vascular strand of the tuber has been used as evidence for regarding the tuber of fertile plants as morphologically a branch (p. 322). It is therefore of the greatest importance to find that the gap is such a characteristic feature in the anatomy of fertile plants. ${ }^{1}$

Other evidence was found in the fact that the tuber stele of the plant first described makes a sharp bend as it passes out, thus suggesting such a change in the direction of growth of the organ as the branch theory of its morphology would involve (Fig. 4, A, t). In the majority of fertile plants this is not the case, for the tuber strand follows, almost as soon as it is free, a direct downward course, but stelar tissue is sometimes found above the level at which the tuber stele is given off (Fig. 5, sects. 2 and 3 ), and doubtless represents the definite bend seen in a better-differentiated plant. That the difference is chiefly one of degree may be seen by comparing the large tuber of Fig. 4, A, with the left-hand tuber of Fig. 4, B.

In this connexion it is also important to note in Fig. 5 how the form of the tuber stele changes as it passes out. When first free, it consists in cross-section of a horseshoe-shaped mass of xylem, with the arms of the horseshoe turned towards the main stele (sect. 4), but by the time it enters the shaft of the tuber (sect. 6) the curvature is in the opposite direction. The two positions of the gap in this single strand correspond to the two gaps seen in Fig. 3, sect. 6, where the stele of the tuber is cut in two places below the bend. We have, therefore, additional evidence that the tuber is an organ which, in the course of specialization, has made a definite change in its direction of growth. It is interesting that features similar to the above are shown by the steles of several other well-developed tubers.

Before leaving the subject of the course of the tuber stele, reference should be made to its behaviour as it traverses the shaft of the tuber. Not infrequently the tuber stele diminishes rapidly to a slender strand of tracheides, and dies out before the swollen end of the tuber is reached. In the larger specimens, on the other hand, the horseshoe form of the stele may be retained until it nears the swollen region, where it breaks up to form several separate strands. By further subdivision the tuber stele forms an irregular sheath of tracheides in the tissue surrounding the bud of the storage tuber. ${ }^{2}$ These tracheides, which are little lignified and difficult to distinguish from the cells of the ground tissue, die out before the base of the bud is reached. Their presence in the largest tubers is

1 The possibility of the gap being foliar, which was suggested by Wernham, is rendered still less probable by recent work, which dissociates very completely the Ophioglossaceae from the Lycopods. Tmesipleris, even if the stelar gaps are foliar, which is doubtful, is more commonly regarded now as ahowing Sphenopsid rather than Lycopsid alliance. Moreover, the 'organe de Mettenius', which Wernham suggests may be the vestige of a megaphyllous leaf is in reality a stage in the reduction of one of the normal leaves of the plant (p. 326).

2 This sheath of tracheides was described and figured by Bertsand, loc. cit., 188 . 
doubtless connccted with the need for a more abundant water-supply. The more primitive features of the tuber would not be looked for in the long shaft of the tuber, which is clearly an adaptation to a geophytic habit, but in that part of the tuber most closely connected with the main axis. Such features have already been found in the origin of the tuber stele, and others will be dealt with in the following section.

\section{c. Leaves connected with the New Tuber.}

Mettenius, in his memoir of Phylloglossum, describes a small tongueshaped body, frequently found above the new tuber. This structure he regards as an atrophied leaf, since, in his material, it was connected by transitional forms with the normal leaves of the plant. ${ }^{1}$ A similar body was observed by Bertrand, and named the 'organe de Mettenius', but his material showed none of the stages which led Mettenius to his conclusion. ${ }^{2}$ Bower, however, states that, in several of the mature plants he examined, a leaf placed above the new tuber was frequently smaller than the others, and he suggests that it corresponds to those structures observed in a similar position by earlier writers. $^{8}$

The aim of this section of the paper is twofold; in the first place, to confirm the work of Mettenius by showing that the organ which bears his name is indeed a reduced leaf, and, secondly, to show how some of the lower leaves of the plant are connected with the new tuber.

The general structure of the tuber, the bud of which is sunk at the base of a narrow channel, has already been described (p. 3I7). The mouth of this channel is situated on the outer surface of the tuber, often at the base of a small hump of tissue borne in the angle between the new tuber and the peduncle of the cone. In some cases this hump of tissue can only be observed in a microscopic examination (Fig. 4, B, r.l.), in others it may be seen with the naked eye or with a lens, and recalls then the tongueshaped body described by Mettenius and Bertrand (Fig. 2, r.l.). A vascular supply is generally found, consisting of a slender strand of tracheides, which dies out before the tip of the organ is reached (Fig. 5, sect. I, r.l., and Fig. 3, sect. I). Occasionally, in place of this tongue-shaped structure a small but otherwise normal leaf is found, the 'supernumerary leaf' of Professor Bower. Such a leaf is shown in Fig. 2, $a$, s.l., and appears in section in Fig. 3, sect. I. A complete series of transitional forms connects such leaves with the various structures described above, and there is no doubt that all are merely stages in the reduction of one of the normal leaves of the plant.

\footnotetext{
1 Mettenias : loc. cit., p. 99 .

Bower : loc. cit., I 886, p. 670.

Bertrand : loc. cit, 1885 .
} 
The occurrence of a stunted leaf in such a pasition is explained by its connexion with the tuber. Earlier in this paper $(p .324)$ reference was made to the fact that a leaf-trace, travelling in the cortex opposite the ramular gap, was connected with the stele of the tuber. Such a leaf-trace may belong to a normal leaf, or to a leaf in one of the stages of reduction just mentioned. So constant is this feature in fertile plants, that of fifteen tubers examined, only four were found unconnected with any leaf, and these were borne by small plants with relatively few leaves. Moreover, a tuber is frequently found bearing more than one leaf, as in the plant of Fig. 5, where the steles of two normal leaves and one which is much stunted are connected with the stele of the new tuber. Plant $b$, sketched in. Fig. 2, was conspicuous both for the number of its leaves and for the fact that they were arranged unequally round the axis of the cone. It was found that from one tuber five leaf-traces were given off, from the other only two.

The leaf-traces are generally given off from the base of the tuber stele, that is, from the part near the parent axis, where the more primitive characters are likely to occur (p. $3^{26}$ ), but in 'one case a small vestigial strand passed off from the tuber stele at some distance down the shaft (Fig. 4, B, r.l.).

The fact that leaf-strands pass off from the stele of the storage tuber, some of them supplying leaves which are quite indistinguishable from those borne by the main axis, confirms the view that the tuber of Phylloglossum is a specialized branch. Moreover, the stunted growth of certain leaves may be correlated with this specialization, since imperfectly developed leaves are always those connected with a storage tuber.

\section{Vascular Anatomy of Sterile Plants.}

The resting tubers of Phylloglossum always produce, on germination, one or more roots, a tuft of the characteristic cuneiform leaves, and a new storage tuber, but the spore-producing part of the plant may be absent. In these plants some of the leaves on the side from which the tuber is given off may be reduced, but the different stages in reduction observed in fertile plants were not all found. No sterile plant with a second new taber has been recorded.

Serial transverse sections of a sterile plant show, in general, the following stelar structure: At the base of the plant the entering rootstrands unite with the small strand of the tuber to form a stele, consisting of a core of xylem, which seldom shows a definite medulla. From this stele leaf-traces are given off, each consisting, as in fertile plants, of a single mesarch strand of xylem. As the leaf-traces pass into the cortex the stem stele diminishes in size, breaks up, and, before the leaf-bases are free, 
completely disappears. This apparent disintegration and dying out of the upper part of the stele in sterile plants is the most striking feature in their anatomy, and one demanding an explanation. Earlier in this paper (p. $32 \mathrm{I}$ ) a plant was described in which the stele of a storage tuber made a sharp upward bend as it passed out, and this bend was taken as indicating a change in direction of growth. It may be noted that sections through this bend correspond very closely with transverse sections taken at a certain level in sterile plants, and the apparent dying out of the upper part of the stele in these plants may be due to a sharp bend in the axis. If this be so, sterile plants must consist of a slender unbranched axis, which bends over and forms the annual storage tuber. In support of this is the fact that Professor Bower, working on the ontogeny of the yearly growth of sterile tubers, identified the growing point of the new tuber with the apex of the stem itself. ${ }^{\mathbf{1}}$

In the largest sterile plant examined, the course of the stele is somewhat different from that described above, the chief difference being that it is for a short distance medullated, as are the steles of fertile plants, and the tuber strand, as it passes out, assumes the characteristic U-form. Moreover, the medullated stele shows a break which, corresponding in position to the tuber stele, recalls the ramular gap of fertile plants. The upper part of the stele is, however, apparently lost among the leaf-traces as in other sterile plants.

The $\mathrm{U}$-form of the tuber stele, and the break which occurs in the stem stele above the level of its exit, are difficult to bring into line with the conception of sterile plants suggested above. They are explained, however, if, on analogy with fertile plants, it be assumed that branching has occurred on the formation of the new tuber, but that here the fertile branch has been arrested early in its development. It seems probable, therefore, that two conditions may exist in sterile plants: that a sterile plant may consist either of a simple axis, concerned only with the formation of a storage organ, or of an axis which has divided, one branch forming a tuber, the other being completely abortive, thus representing a condition intermediate between the small sterile and the simple ${ }^{8}$ fertile plants. In either case the anatomy of sterile plants bears out the conclusion that the tuber of $p / z y l l o-$ glossum is the specialized terminal part of a leafy axis.

\section{Branching in Phylloglossum.}

Phylloglossum has hitherto been regarded as a typically unbranched form of Lycopod, the rare cases of branching which have been recorded being restricted to the cone-bearing axis. Professor Thomas states that

\footnotetext{
1 Bower : loc. cit., 1886.

' 'Simple' here refers to fertile plants with a single new tuber in which the axis is, therefore, only once brauched.
} 
about one plant in 2,000 may possess a forked strobilus, the two arms being equally developed. 1

If, however, we hold that the tuber is morphologically a branch, branching in Phylloglossum can no longer be regarded as a rare occurrence, since it happens at least once in the yearly growth of every fertile plant. Moreover, the New Zealand form not infrequently produces more than one new tuber during the season, and in such cases two acts of branching must have occurred. ${ }^{2}$

When two new tubers are formed they may arise on opposite sides of the plant, with the old tubers between them (Fig. 2, b), or near together on the same side (Fig. 2, c). In this case the habit of the plant suggests that the two tubers are the result of a dichotomy, and this is supported by its stelar structure. A medullated stele is found in the peduncle, and is later interrupted by a gap, below which, on the same side of the plant, a curved band of xylem passes out into the cortex. So far there is close agreement with the stele of a fertile plant with one new tuber: the difference lies in the behaviour of the branch stele. Whereas it normally passes, with some modification in form, down the shaft of a single tuber, in the plant now under discussion it gives rise to two smaller strands, and thus supplies two tubers. The daughter steles are slender strands, showing no characteristic gaps, since the division takes place when the original stele is an irregular curved band of xylem. The duplication of tubers in this way is consistent with the conception of the tuber as a specialized part of the axis, and affords an example of double branching in Pliylloglossum.

Double branching also occurs in the axis of plants bearing a new tuber on two opposite sides. The anatomy of one of the three plants showing this feature has been fully described (p. $3^{18}$ ), and, since the others agree with it in general structure, it is not necessary to do more than refer to the plan of the stele. ${ }^{3}$

A large stele is formed at the base of the plant by the entering rootstrands. This divides, and the smaller product of the division supplies one of the new tubers. The larger of the two steles divides again, a small strand passing out to the second new tuber, while a large medullated stele passes up the peduncle of the cone. The distance between the two points of branching is so short that the tubers may appear to arise at the same level. That this is not the case is shown by the stelar anatomy (Figs. 3 and $4, a$ ).

In these plants the new tubers have been formed by two successive

1 Thomas : loc. cit.

2 Thomas states that, while plants with one taber are still in the majority, two tubers are frequently formed.

In one case the axis apparently branches twice, but the stele of one new tuber is unconnected with the vascular tissue of any other part of the plant. This can only be regarded as an anomaly resalting from the reduction which the plant has suffered in the course of adaptation to its environment. 
acts of branching at the base of the axis, which finally terminates in a cone. In the previous examples the duplication was due to a dichotomy of the branch, which more frequently forms a single tuber.

Thus, not only is branching found occasionally in the strobilus of Phylloglossum, but normally in fertile plants on the production of each new tuber. It can, therefore, no longer be said that Ploylloglossum is characteristically an unbranched form.

\section{CONCLUSION.}

The interest which has been manifested in the monotypic genus, Phylloglossum, since its discovery in 1843 , has centred round its most characteristic feature, the annual storage 1 uber.

Treub saw in it a resemblance to the organ of $L$. cernumm, which he designated a 'protocorm,' regarding it as of phylogenetic significance. ${ }^{1}$ In this way he initiated a confusion which has been at the base of our difficulty in interpreting the true morphology of Phylloglossum.

With the increase of detailed knowledge of the embryogeny of Lycopods, the inconstancy of the 'protocorm' has been more fully realized, and opinion as to its primitive nature has been modified, the present tendency being to regard it as an 'opportunist local swelling', of physiological rather than of phylogenetic significance.?

This new conception of the 'protocorm' has not, however, helped to elucidate the problem of the morphology of Phylloglossum, if the old comparison with the embryo of $L$. cermusm still be made. Except inasmuch as both the 'protocorm' of L. cernum and the tuber of Phylloglossum are manifestations of the tendency to local swellings seen throughout the family, the resemblance between them is purely superficial.

The present work, by detailed anatomical investigation, has shown that the tuber of Phylloglossum is a highly specialized leafy axis, the terminal bud of which functions both as a means of vegetative reproduction and as an organ of perennation. Though different in appearance and structure, the tuber of Phylloglossum is comparable with the resting buds of $L$. inundatum and the 'tubers' of certain Indian species of Selaginella. ${ }^{8}$

The position which Phylloglossum has hitherto occupied in the family Lycopodiaceae is rendered less isolated, since it can no longer be regarded as typically unbranched. On the other hand, the marked geophytic specialization, the mesarch character of the xylem, and the medullation of the stele, together with long established custom, justify the retention of separate generic rank.

\footnotetext{
1 Treub: loc. cit. 8 Bower : loc. cit., 1914.

Bancroft, N.: Ann. of Bot., vol. xxviii, 1914 , p. $68_{5}$.
} 
VIII. Summary.

I. That the tuber of Phylloglossum is, in fertile plants, a modified branch is supported by the following facts:

I. A gap is left in the stele of the main axis by the exit of the vascular strand of the tuber.

2. The stele of the tuber often shows a corresponding gap.

3. The tuber bears leaves, some of which are considerably reduced.

II. In general, sterile plants consist of a simple axis, the apex of which has formed a storage tuber. It is possible that, in the larger specimens, branching occurs as in fertile plants, but the arm, which in the latter produces a cone, is in sterile plants arrested early in development.

III. The tuber of Phylloglossum can no longer be compared with the protocorm of Lycopodium cernuum, but the two genera are brought nearer together, since Phylloglossum has proved to be not characteristically an unbranched form.

In conclusion, I wish to thank Professor Benson for suggesting this work, and for her helpful criticism during the course of the investigation. 
